\title{
SUDDEN DEATH MEMORIALS IN BUCHAREST: DISTRIBUTION IN TIME AND SPACE
}

\author{
Irina Stahl \\ Institute of Sociology, Romanian Academy, Bucharest, Romania \\ e-mail:irinastahl@yahoo.fr
}

\section{Barry L. Jackson}

Bloomsburg University of Pennsylvania, U.S.A.

e-mail:bleejack@yahoo.com

\begin{abstract}
Only one year after the 1989 revolution, which ended the communist rule of Romania, Bucharest experienced a significant increase in the placement of memorials commemorating people who died unexpectedly. This study examines the unique set of circumstances which lead to the resurgence of this long-standing practice and the reclamation of the urban public space for placement of these memorials. A total of 290 sudden death memorials, representing 313 individuals, were identified in Bucharest between 2000 and 2018 .
\end{abstract}

Keywords: Bucharest, evolution in space, evolution in time, public space, religious practices, roadside memorials, sudden death memorials 


\section{Introduction}

Shortly after the violence of the 1989 events which lead to the fall of the communist regime in Romania, a variety of memorials and monuments dedicated to the 'heroes of the revolution' appeared throughout Bucharest (Stahl 2010; 2013). Memorials rapidly proliferated the city's public space. Some memorials were erected in central places where many people lost their lives. Still others appeared near churches or in front of military units, which had suffered losses during the violent confrontations. The victims' family members erected some of the memorials, while others were constructed at the initiative of the victims' associations or local authorities who were eager to show their repentance for past wrongs and their solidarity with the bereaved. Regardless of the initiator of the individual memorial, each bore the same cross-shape. The city, little by little, was studded with crosses: "clear markers of the recent political change and the freedom of religious expression that it engendered" (Stahl 2013: 893-894).

This 'memorial mania' (Doss 2010) which dominated most the 1990s and continued throughout the 2000s encompassed what, at the time, was called "the national reconciliation process". The construction of official state monuments gave an opportunity to the now former communists to re-enter the public scene and to mourn the loss of innocent victims, together with their former opponents. The monuments served as the common ground where former enemies could meet and take part, side by side, in the numerous commemoration ceremonies.

Within this context unofficial cross-shaped memorials made their appearance in the city centre. These memorials bore a personal touch providing the victims' names, ages and occupations along with the circumstances of their deaths. Sometimes pictures or a few words were added telling of the family's or friends' grief. Additional memorial crosses, inspired by earlier memorials, soon followed, marking places where people's lives ended under various circumstances, but as unexpectedly as the deaths of the heroes of the 1989 revolution. Although most memorials are dedicated to road accident victims, others are for victims of more unusual causes of death including falls, electrocutions, strokes, suicides, drownings, and even murders (Stahl 2013: 894; 2010: 388).

Memorials in Bucharest have specific characteristics, related to their appearance and function, which make them stand apart from most examples referred to Western academic literature. Made out of durable and long-lasting materials, 
memorials in Bucharest are intended to be permanent not 'temporary', nor 'ephemeral', as the 'grassroots memorials' (Margry \& Sánchez-Carretero 2011), nor do they represent forms of social action. A more suitable term to describe them would be 'roadside memorials'. Memorials in Bucharest are in their large majority crosses, so they could be referred to as 'roadside crosses' (Everett 2002). The sight of a cross beside a road is so common in the public sphere in Romania that it has become a symbol of road accidents and has been used by Traffic Police for several years as a symbol in their safe driving campaign. However, although usually located next to roads, memorials in Bucharest are not always related to road or traffic accidents, but rather to the fact that roads are the main spaces of circulation of the continuously moving urban population. Compared to official Traffic Police data, the location of memorial crosses does not correspond with the roads or places with elevated accident rates. Memorials sometimes can be found in the most unexpected places such as: next to rail tracks in the Central Railway Station; under the windows or in the gardens of apartment buildings; next to playgrounds or parking lots; on the riverbank; or in the middle of the park. Deaths that occur in public spaces are marked, regardless of their nature. Although memorials vary, in Bucharest, they all have one thing in common, which is the very event that underlies their erection: the sudden, unexpected and thus unprepared-for death. For this reason, Stahl called them 'sudden death memorials' (Stahl 2013), a term that more appropriately describes the reason for their existence. From this perspective, the Romanian memorials seem to be similar to memorials in Southern and Eastern Europe, such as the former Yugoslavia $^{1}$ (Rajković 1988a; 1988b) and Russia (Yudkina \& Sokolova 2014). The Greek proskynetári, although quite similar in function to the Romanian crosses, are different in their appearance, as they represent miniature Orthodox Churches (see Panourgiá, qtd. in Everett 2002: 20). Various nations in Latin America, such as Chile and El Salvador, also exhibit memorials with a similar purpose (Woolf \& Escobar, qtd. in Everett 2002: 18).

These sudden death memorials are not shrines in the sense that Fraenkel (2011) understood a 'shrine'. She uses the term in a broad context as a place "where written material is concentrated and intimately mixed with candles and flowers, and with a broad range of other objects such as toys, flags, ribbons, clothes, etc." (Fraenkel 2011:233). This description does not correspond with the sudden death memorials in Bucharest, most of which consist of a simple metal cross. As for the intrinsic idea of "adoration and praying practices at a religious, 
holy site" insinuated by the term 'shrine' (Margry \& Sánchez-Carretero 2011: 23), it has to be mentioned that although in Romania the memorial cross is occasionally consecrated by priests, sprinkled with holy water and smoked with incense, the place it marks is not a place of veneration. It is however, a place where one prays for the soul of the deceased. It is in this regard only, that memorials in Bucharest address the public and require participation of strangers, as is the case of 'spontaneous shrines' described by Santino (2006: 12). Field interviews revealed that, it is not uncommon for strangers to leave flowers at memorials, or to light a candle in memory of the deceased, or rather to ease his soul.

Only a few particular memorials in Bucharest are 'performative' in the sense given by Santino (2006; 2010). These are the unique memorials raised in memory of the 'heroes of the revolution' and for the victims of the violent demonstrations of miners in 1991. The result of violent, political or social confrontations, these memorials make a statement, they are, using Santino's words, 'the silent witness' (2006: 12). Long before any official monument was erected for these victims, ${ }^{2}$ before anyone knew their names; small, insignificant, fabricated crosses were the only indicators of their sacrifice, the only ones to tell their story.

As the number of sudden death memorials in Bucharest continues to grow, a pattern of their distribution in space and time has emerged. The current article investigates only the matter of their distribution in space and time. An in-depth examination of the form and function of these memorials is reported elsewhere, as are the victims' demographic data (Stahl 2010; 2013).

\section{Theories of Mass Behaviour}

Although Doss (2010) remarked about an extensive variety of memorials commemorating the dead and their rapid and prolific appearance as 'memorial mania', this could be an apt expression for the more narrowly defined sudden death memorials in Bucharest as well. What is at the root of this manic growth? In order to answer that question, it is necessary to explore several relevant theories. Ogunlade (1979) states that social restraints are generally group derived and form the basis of society and culture. When the social restraints are not group derived, but are imposed by an external authority, the risk to individuals who deviate from the imposed expectation is increased by a degree equal to the 
threat of force and the probability of punishment. Communism used both of these elements to control religious practice and traditional folk beliefs among the populace to reshape Romanian society and culture.

Associative imitation theory (Heyes \& Ray 2000), also called 'contiguity', asserts that information and behaviours which constitute culture do not originate from within the individual, as Bandura thought (Bandura 1986) but, are passed from generation to generation. This transmission theory allows for macro and micro [an entire society or individual family unit] passage of traditional behavioural expectation. The degree to which a society and its culture can be reshaped is dependent on the strength of collective memory. As long as some memory or record of a previous cultural behaviour or belief exists, it can re-emerge. The speed and strength of re-emergence is equal to the prevalence of the memory or record of the previously accepted behaviour or belief. The more widely practiced the traditional behaviour is, the more rapidly it can be restored when external constraints are removed. Additionally, behavioural reemergence may be aided by social facilitation (Wheeler 1966). One individual's acts serve as "a releaser for the same behaviour in another or in others", which in turn promotes the same "action in the whole group" (Thorpe 1956: 120). A widely held cultural value or behaviour of long-standing, once prohibited, may quickly re-emerge after the prohibition and threat of punishment are removed. The erection of crosses is not a recent phenomenon. Accounts from the seventeenth century suggests the pre-existence of large numbers of crosses along Romanian roadsides (e.g. Călători 1973: 206; Călători 2001: 1247, 1291).

Gustav Le Bon was first to identify the social phenomenon of 'behavioural contagion', a type of social influence. He used the term to describe undesirable aspects of social behaviour within a crowd of people (Le Bon 2009 [1895]). Since the appearance of his work, in late nineteenth century, the theory has undergone many refinements and expansions (Stephenson \& Fielding 1971) and is no longer understood to relate solely to undesirable behaviour. Still central to this prevalent theory is the concept that a crowd can reduce personal restraint of behaviour engendering a group identity (Redl 1942). Within group identity, there is a loss of fear and restraint of one's behaviour, which can lead to deviation from acceptable social norms. This understanding of behavioural contagion also implies a sense of 'deindividualization' as further defined by Festinger, Pepitone and Newcomb (Festinger et al. 1952). People in groups lose a personal sense of responsibility and independent identity, which are 
subsumed into the group's identity (Freedman et al. 1980). Thus, the group becomes responsible, not the individual, and the normal social restraints are diminished. Ralph Turner found that when one or more people violate the established societal norms, it becomes easier for each successive person to transgress the prohibition (Turner 1964). Each successive person who performs the behaviour serves as an endorsement to others to behave in a similar manner. This concept is much like social facilitation. The initiator of the 'deviant' behaviour establishes it and subsequent individuals set a pattern, which, if sustained by an increasing number of people, reaches a critical threshold and becomes the new social norm. Hence, the behaviour is normalised and can become an expected social behaviour embedded within the cultural context.

A further concept useful in the understanding of group behaviour comes from the 'Werther effect'3 presented in David Phillips' work (Phillips 1974). When a well-known or highly admired person performs an action, that behaviour appears 'endorsed' and provides support for others who wish to act in a similar manner (Phillips 1974). In this way, a once rare behaviour can become commonplace. In 1979, Ogunlade defined behavioural contagion as a "spontaneous, unsolicited and uncritical imitation of another's behaviour" (Ogunlade 1979: 205). His model contains four conditions he found present in contagious behaviour; most importantly, the initiator of the behaviour serves as a positive example or reference to observers of the behaviour. Unlike Le Bon, Ogunlade does not assume the undesirability of group behaviour in his model of behavioural contagion.

According to Freedman the appearance of individual behaviour may manifest in two forms: point clusters or mass clusters. In point clusters, activities or behaviours tend to occur within a related time period and within a contiguous space or spaces. Clustered behaviours, which are not grouped in contiguous space, but are grouped within a related time-period, are mass clusters (Freedman et al. 1980). Two additional concepts are valuable in any discussion of behavioural contagion: size [number of members] and density [proximity of members] (Freedman et al. 1980). The size of a group is of less importance than how tightly the group members are spaced. The greater the density the more contagious the behaviour. Widely spread rural populations are less affected by non-group, externally imposed constraints, as previously discussed, and traditional behaviours are more likely to persist when compared to more densely populated urban environments. Concomitantly, urban populations are more 
prone to behavioural contagion due to their density. Hence urban populations experience a greater impact of non-group externally imposed constraints while they are also more likely to undergo increased behavioural contagion upon the removal of the externally enforced constraints.

\section{Methodology}

In the year 2000, a longitudinal study of sudden death memorials located within the city limits of Bucharest was undertaken. The study is now in its $19^{\text {th }}$ year. Repeated fieldwork campaigns have so far revealed a total number of 290 memorials. Each time a memorial cross or other monument was located it was photographed and a note was made registering its location and structure. After registering a sudden death memorial, it was plotted on a city map. This plotting allowed researchers to return to the field site and examine the memorial and its surrounding in greater detail. This process proved valuable in finding neighbouring memorials and lead to collection of direct source materials. Direct sources consisted of several short interviews with shopkeepers, neighbours, and passer-by's in the area where memorials were located. These provided needed information regarding the cause of deaths and dates of placement of the monuments. Furthermore, three extended interviews with priests who had been called upon to bless these memorials provided valuable information. A two and a half-hour, in-depth interview with two family members who had lost two loved ones in a car accident and had erected a memorial to their memory, was also revealing. ${ }^{4}$

Quantitative data concerning the distribution in space and time of the memorials in addition to gender, age at death and other information about the persons to whom they had been erected was recorded. Subsequently, information was gathered from indirect sources, such as printed or online articles and broadcast media.

Several memorials disappeared over the course of fieldwork. As they still had a role in the distribution, as will be shown, they were kept in the study for plot mapping and statistical purposes. The locations and dates of monument the erections were graphically plotted to visually depict emergent patterns. 


\section{Findings and Discussion}

The existance of sudden death memorials in Bucharest is not exceptional. Similar memorials are visible all over Romania and, despite a few regional differences, they are very much alike. What is exceptional, however, is the stunning increase in their numbers after 1989 [refer to Figure 3 and Figure 7 below]. Over the past three decades the spread of sudden death memorials in Bucharest has been considerable, encouraged by permissive legislation which does not impose sanctions or restrictions on those who install them, either on public or private land. The situation is quite different in the neighbouring Republic of Moldova, where memorials were the object of a special order issued by the Minister of Transportation, who demanded their express removal before the end of 2016. Western countries, and fifteen American states (Margry \& Sánchez-Carretero 2011: 14) have also taken legal measures to stop the spread roadside memorials. Opposite legal measures are in place in New Mexico, where damaging descados (resting places) is a criminal offense and the family must be notified before necessary removal. In Romania, local authorities discourage new installations, when asked for permission. The two bereaved family members interviewed inquired at the Bucharest city hall before installing their memorial cross. Although it was not illegal, they were advised not to go ahead with their plans, so that the city would not resemble "one big cemetery".

Memorials are generally regarded with respect in Bucharest and even protected; to remove them would be considered callous, even sinful. However, public opinions on this issue are divided. Individuals opposed to memorial placement feel personal tragedies should not be imposed on others. There are those who are sympathetic toward the bereaved and are tolerant, if not accepting, of this traditional practice. Road workers interviewed for this project declared that if necessary, they only temporarily relocate the roadside memorials, taking care of putting them back in place once their job is done. People living close to memorials, mistaking the researcher as a city official, have repeatedly asked that the memorials not be removed, stressing the tragedy behind them. Nevertheless, over the years, a number of memorials have disappeared, mainly due to roadwork and city planning.

Why are these memorials highly regarded and why was there such a rapid proliferation of memorials in the immediate post-communist period? There are several theoretical answers to these questions. Ogunlade's (1979) 'group 
versus non-group derived behavioural constraints theory' suggests that the collapse of communist rule and the resultant freedom to engage in religious and ancient traditional practices provides a partial answer. During the communist regime overt religious expression was restricted in Romania and more strictly enforced in the national capital, Bucharest, than elsewhere. Religious restrictions ended with the removal of communist rule. When external threats are removed, previously prohibited cultural behaviours can re-emerge.

Historical sources mention the existence of large numbers of crosses alongside Romanian roads as far back as the seventeenth century (e.g. Călători 1973: 206; Călători 2001: 1247, 1291). Their presence continued in Bucharest until they were removed and transferred to museums and churchyards under communism. Despite communist prohibition, the erection of commemorative memorials was never wholly abandoned in Romania, although it was more common in rural regions than in urban environments where the threat of force and the probability of punishment were greater. Judging by the year of death inscribed on the memorials, the oldest memorial registered in Bucharest dates from 1974 (Figure 1). In total only sixteen memorials erected during the communist period were inventoried. Perhaps there were more which may have been removed by government officials during that period. Undoubtedly the fear of punishment curtailed the long-standing cultural practice of commemorating the dead with a cross at the scene of death. Although curtailed, these sixteen memorials testify to the continuation of the practice even under communism. The cross therefore was not a new element in the cityscape of Bucharest and may well explain the re-emergence of sudden death memorials, but perhaps not the rapidity of this re-emergence. The case described in the former Yugoslavia (Rajković 1988a; 1988b), where communist authorities had a difficult time restraining the expansion of the practice, only confirms this assumption.

In the communist era, however, memorial placement was done in a rather discreet way, thus reducing the threat inherent in non-group derived social restraints identified by Ogunlade (1979). The memorials were smaller, less elaborate, and usually handmade in comparison to the larger commercially manufactured, more recent memorials. They were mainly located at the periphery of the city, away from the eyes of officials and local authorities (Stahl 2010: 398; 2013: 895). As in the case of other religious practices, the restrictive measures imposed by the communist regime were more visible in Bucharest than in remote rural areas or even other cities, where these traditions 
continued unhindered. Widely spread rural populations are less affected by nongroup, externally imposed constraints (Freedman et al. 1980) and traditional behaviours are more likely to continue.

During communism, Bucharest was heavily industrialised. To meet manpower needs for the newly industrialised city, rural inhabitants were relocated to Bucharest. This influx of rural inhabitants brought with them their old traditions which were repressed in their new home. According to Heyes and Ray's (2000) 'associative imitation theory' their cultural practices would be transmitted from generation to generation and not quickly forgotten. Because communism in Romania lasted little more than one generation, older traditions were not extinguished. The density of rural people in the city and the strong memory of tradition, combined with the removal of restraints, allowed the long-held cultural practice of creating memorials to rapidly re-emerge in the urban public space.

The tone for the re-emergence of the traditional cross/monuments to mark sudden death within the city of Bucharest was set by the monuments to the heroes of the revolution. The example given by the heroes of the revolution served as both an endorsement, as defined by Phillips (1974) and as a positive reference to observers of their actions. As in the case of the former Yugoslavia, the power of the examples was considerable (Rajković 1988b: 177). These celebrated heroes served as models for other monuments to be placed in public space (Stephenson \& Fielding 1971). Ogunlade (1979) speaks of how a positive role model serves to advance imitative behaviour. The example of these powerful role models in conjunction with the reappearance of group derived social norms lead to the re-emergence of the memorials. The rapid proliferation is explained by Turner's theory (1964) of behavioural contagion as well as by Heyes \& Ray (2000). When the externally imposed forces of communism were removed social facilitation (Wheeler 1966; Thorpe 1956) took over. Even former communist leaders then publicly embraced religion, and conflicts over practice of the cultural tradition within the city ceased. Increasing numbers of individuals began doing what they had wanted to do, i.e. place a cross/monument for the dead and so others, seeing this, also did the same free from the non-group derived prohibitions. Theories posited by Turner (1964) and Heyes \& Ray (2000) predict such behaviour. The behaviour grew within the city to a point where it was both acceptable and perhaps expected of families. The density (proximity of members) of the city that once prevented people from violating the externally, non-group derived rules now facilitated behavioural 
contagion (Freedman et al. 1980). The greater the density the more contagious the behaviour.

The assertion of group derived social norms appeared immediately following the December 1989 revolution with the establishment of seven memorials to the 'heroes of the revolution'. Another six sudden death memorials materialised in 1990 (Figure 1). Interviews conducted during fieldwork revealed that people do not always erect a memorial immediately following a death but do so by the first anniversary of the death. Consequently, it is difficult to date the actual construction of the memorial thus, for our purposes the date of death, as inscribed on the memorial, served as a reference. During the decade following the revolution (1990-1999) a total of 111 memorials sprung up in the city (Figure 2). The year with the largest distribution of memorials was 2005, with 16 memorials, closely followed by 1999, with 15 memorials (Figure 1). Since 2007 there has been a decreasing trend in the placement of new memorials. The number of new memorials, two, registered in 2016 approximates the prevalence of new memorials during the communist years. The 'memorial mania' seems to be waning. It must be noted that 34 memorials of the total of 290 have an unknown date of origin which may impact this downward trend. Figure 1, shows a clustering of memorial erections in time with intermittent declines and a current downward movement. Figure 2 demonstrates the rapid

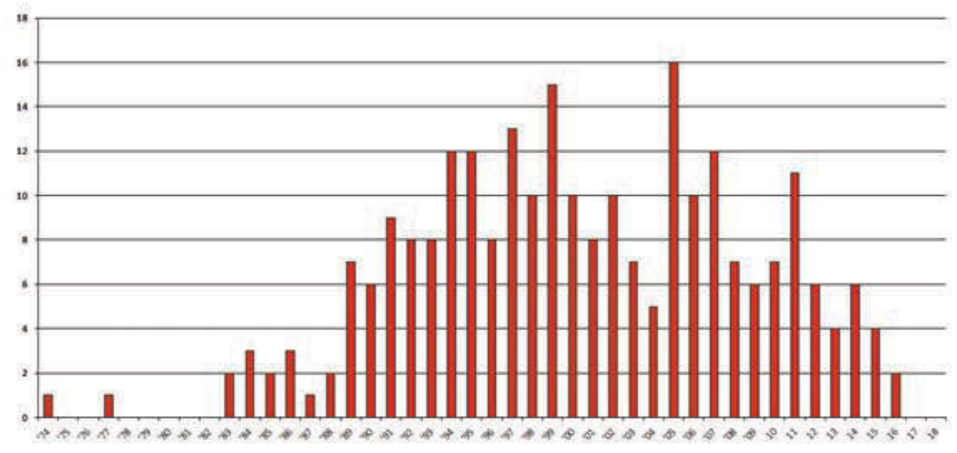

Figure 1. Distribution of memorials by year, taking into account the year of death of the commemorated person. Note: for 34 memorials, the date of death is unknown. 


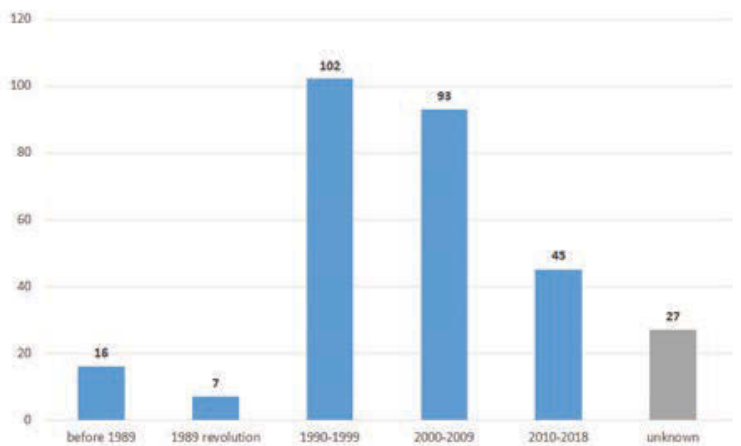

Figure 2. Distribution of memorials by decades in which the sudden death of the commemorated persons occurred.

Note: In Figure 1, the specific dates of death are unknown in 34 cases. However, in Figure 2 seven of these cases could be identified in specific decades.

growth of sudden death memorials in the 1990s and the first decade of this century providing one of two of Freedman's 'point cluster' model (Freedman et al., 1980) criteria, i.e. occurrence within a related time period. The figure also provides evidence of the prior existence of sudden death memorials however limited in number.

Freedman's (Freedman et al. 1980) second criteria for the 'point cluster' model requires the occurrence within a contiguous space or spaces. To determine whether this criterion is met, location mapping by sequence of installation was undertaken. In Figure 3 one can see that memorials erected prior to 1989 were generally well outside the centre portion of the city, thus drawing little attention. These memorials were on roadways exiting the city and were closer to outlining villages than to central Bucharest.

The memorials to the heroes of the revolution are added to the location map in Figure 4. These memorials are more centrally located, near scenes where violence took place in December 1989. Four memorials are clustered very near each other, in the Western section of the city where much of the fighting took place, close to military installations and the former Ministry of National Defence. These memorials appeared in early 1990. 
Sudden Death Memorials in Bucharest: Distribution in Time and Space

\section{Before 1989}

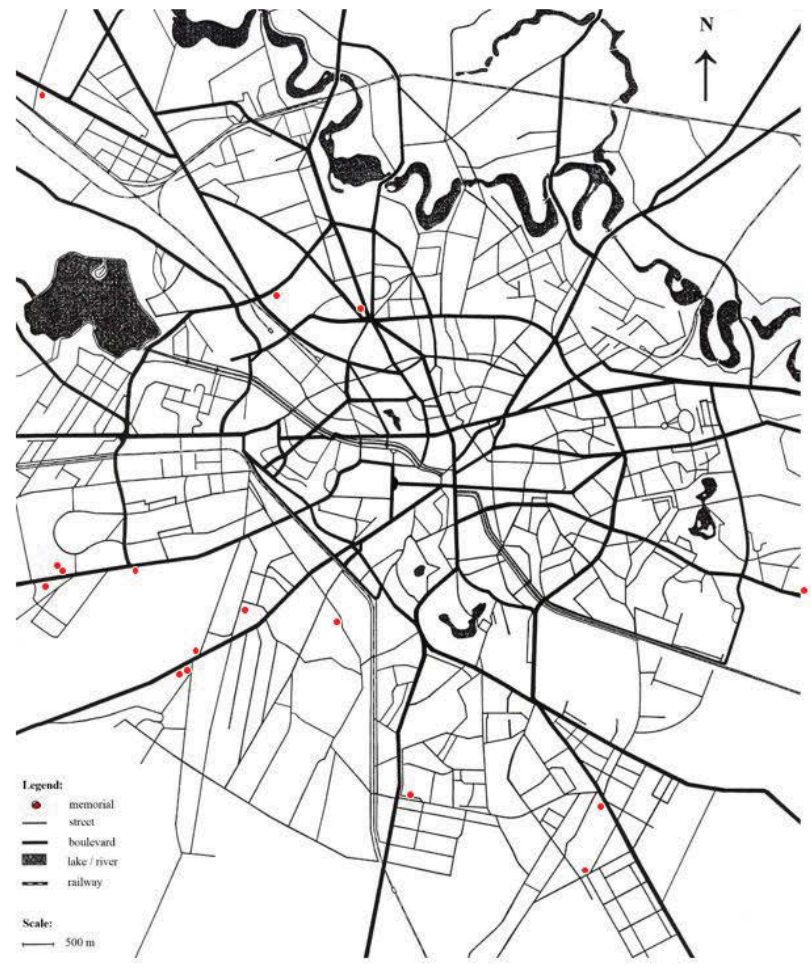

Figure 3. Sudden death memorials before 1989. 
Irina Stahl, Barry L. Jackson

\section{9 revolution}

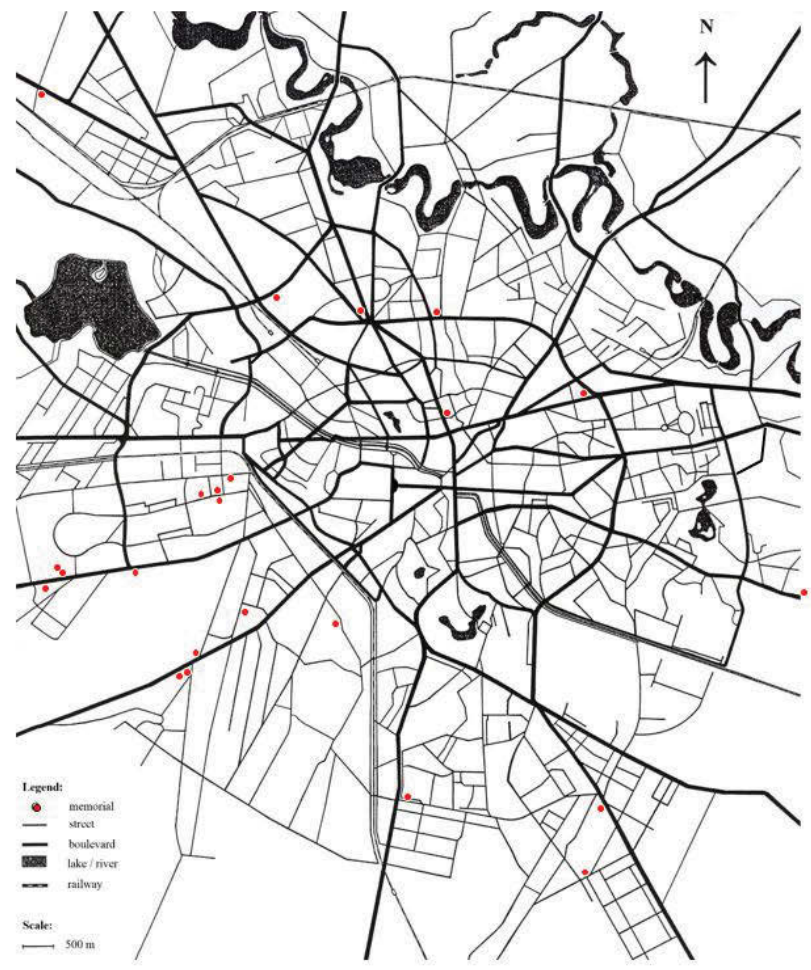

Figure 4. Sudden death memorials related to the 1989 revolution. 
Sudden Death Memorials in Bucharest: Distribution in Time and Space

1990-1999

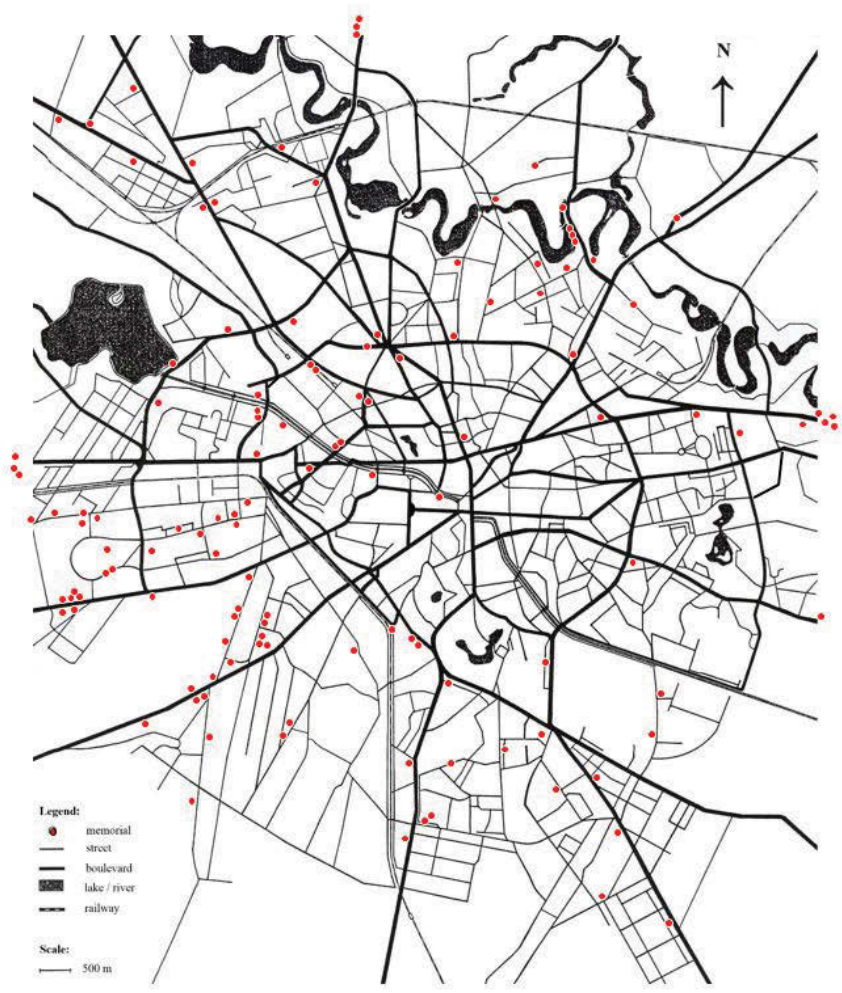

Figure 5. Sudden death memorials between 1990 and 1999. 
Irina Stahl, Barry L. Jackson

\section{0-2009}

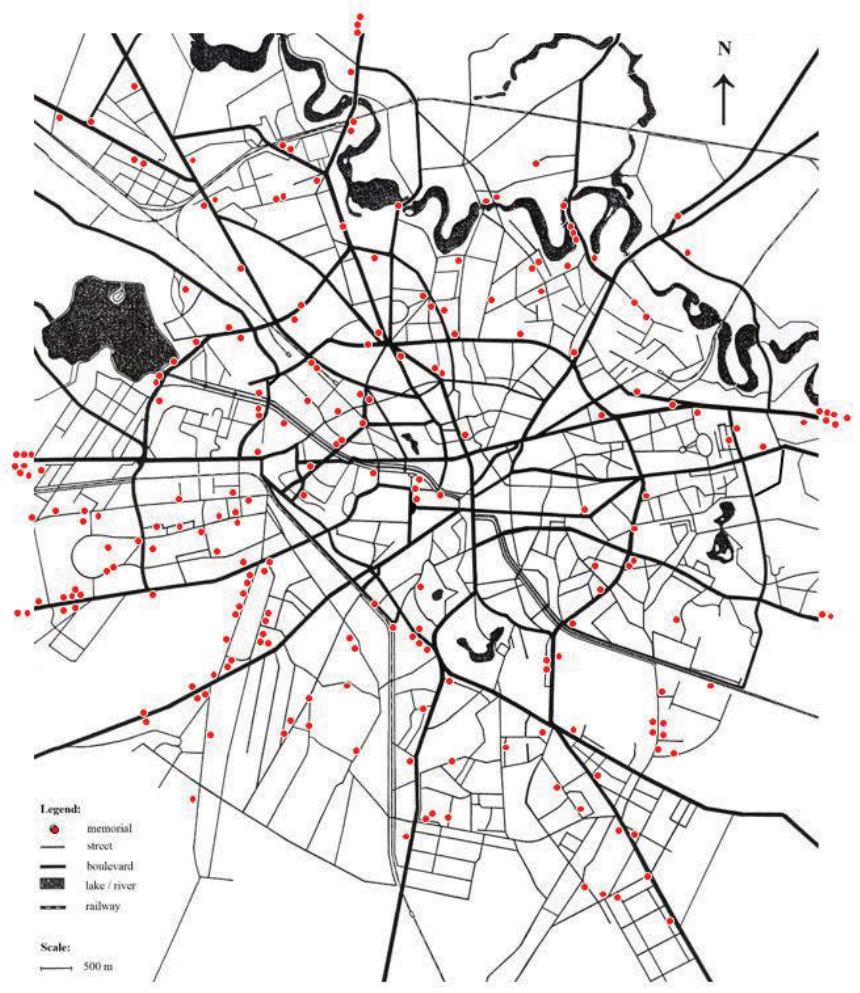

Figure 6. Sudden death memorials between 2000 and 2009. 
Sudden Death Memorials in Bucharest: Distribution in Time and Space

\section{0-2018}

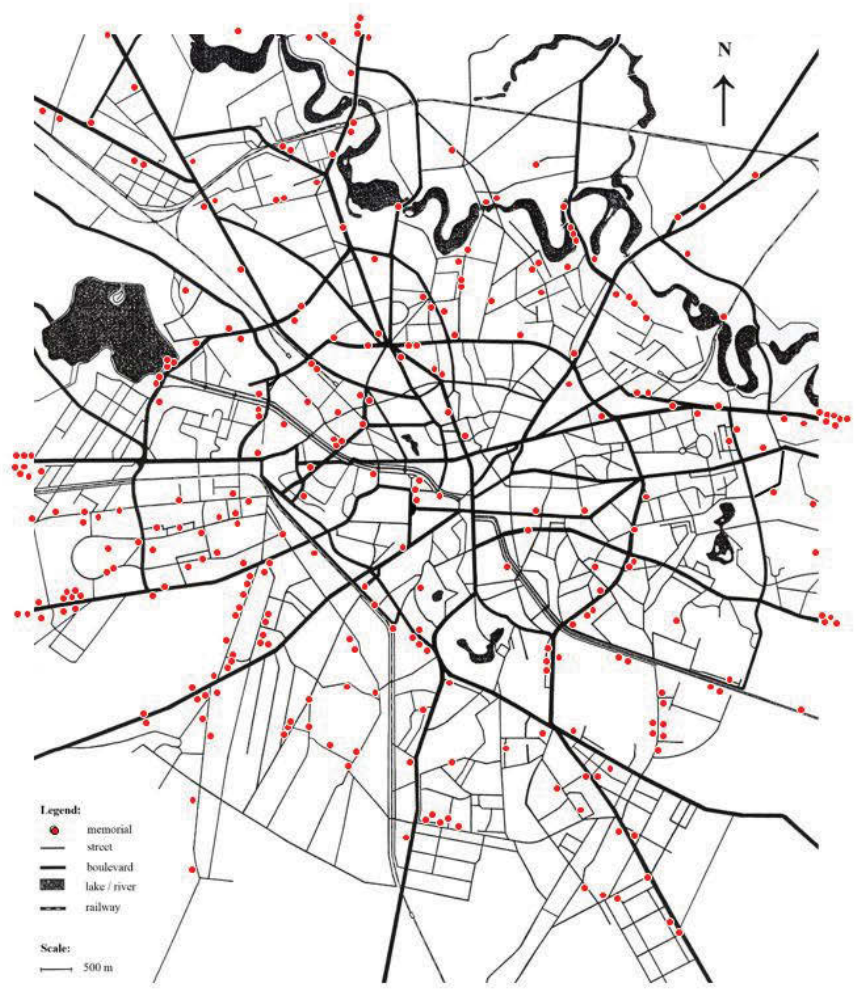

Figure 7. Sudden death memorials between 2010 and 2018. 
Figure 5 shows the locations of 102 new memorials erected between 1990 and 1999. One can notice the widespread placement of the memorials throughout most neighbourhoods within the city. Large new clusters of memorials, with as many as six in a location are apparent. The river bank is also host to five or more memorial sites.

By the first decade of this century memorials stretched from the periphery to the heart of the city and frequently form clusters of 4-8 memorials. Ninetythree additional memorials emerged. Boulevards, streets, tramway lines, the lake and the river banks all have memorials. By the end of 2009 there was a total of at least 218 (Figures $2 \& 6$ ) memorials. The heaviest concentration of memorial sites is found in the Western part of the city, where several memorials dedicated to the heroes of the revolution are located. New memorials have clustered around these areas (Figure 6).

Figure 7 shows all 290 memorials registered in this research. The heaviest concentration of memorials remains in the Western portion of Bucharest, with multiple clusters of 4-8 crosses. However, every part of the city and all major boulevards, numerous well-travelled streets, the tramway lines, the lake and the river banks teem with memorials.

This paper explored the distribution of sudden death memorials in space over time. Multiple theories gave possible explanations for the rapid re-emergence of an ancient practice, one that did not entirely disappear during communism, of erecting memorials for sudden deaths and for their proliferation in Bucharest. Initially the memorials were unevenly distributed but were in contiguous space. Over time memorials became more widespread with multiple clusters in well-travelled locations. By applying Freedman et al.'s (1980) model of contiguous space relationships over distinct time it is reasonable to conclude that criteria for 'point cluster' are satisfied. It must be remembered that memorials are not only related to road accidents and in fact the erection of them re-emerged in a prolific way due to revolution and not a road or other accident. Each memorial gives silent witness to a tragic death regardless of its unexpected location within the city.

\section{Notes}

1 The study was conducted in the 1960s and the 1970s and referred mainly to Croatia, Montenegro and Slovenia. Serbia was not included. 
2 A monument, symbolically named “The Rebirth" or "The Resurrection”, was inaugurated in 2005. Installed in the square were Ceaușescu gave his final speech, it mentions the name of 1058 victims.

3 In 1974 Phillips introduced the term Werther effect to describe the often referred to copycat suicide phenomenon. He named it the Werther effect after the Goethe novel: Die Leidendes jungen Werther (The Sorrows of Young Werther) published in 1774. The main character of the novel committed suicide after being rejected by the woman he loved. It is reported that many young men, finding themselves in a similar situation, hanged themselves dressed in similar manner to the fictional character, Werther.

4 This interview was with the mother and sister of a woman who perished in an auto accident. Her young daughter died four days later from injuries received in the accident. The memorial is dedicated to both, because "that is the place from which they both went away".

\section{References}

Bandura, Albert 1986. Social Foundations of thought and action: A social cognitive theory. Englewood Cliffs, New Jersey: Prentice-Hall.

Călători străini despre țările române [Foreign Travellers on Romanian Lands] 1973, Vol. 5. Maria Holban \& Maria Matilda Alexandrescu-Dersca Bulgaru \& Paul Cernovodeanu (eds.). Bucharest: Editura Ştiințifică.

Călători străini despre țările române [Foreign Travellers on Romanian Lands] 2001, Vol. 10 ( $2^{\text {nd }}$ part). Maria Holban \& Maria Matilda Alexandrescu-Dersca Bulgaru \& Paul Cernovodeanu (eds.). Bucharest: Editura Academiei Române.

Doss, Erika 2010. Memorial mania, Public feeling in America. Chicago and London: The University of Chicago Press.

Everett, Holly 2002. Roadside crosses in contemporary memorial culture. Denton: University of North Texas Press.

Festinger, Leon \& Pepitone, A. \& Newcomb, Theodore 1952. Some consequences of de-individuation in a group. Journal of Abnormal and Social Psychology, 47, pp. 382-389.

Fraenkel, Béatrice 2011. Street Shrines and the Writing of Disaster. 9/11. New York. In: Peter Jan Margry, Cristina Sánchez-Carretero (eds.) Grassroots memorials. The politics of memorializing traumatic death. Oxford: Berghahn Books, pp. 229-243.

Freedman, Jonathan L. \& Birsky, Joanna, \& Cavoukian, Ann 1980. Environmental determinants of behavioral contagion: density and number. Basic and Applied Psychology, 1 (2), pp. 155-161.

Heyes, Cecilia M. \& Ray, Elisabeth D. 2000. What is the Significance of Imitation in Animals? In: Peter Slater \& Jay S. Rosenblatt \& Charles T. Snowdon \& Timothy J. Roper Advances in the Study of Behavior, Vol. 29, pp. 215-245. 
Le Bon, Gustave 2009 [1895]. Psychology of Crowds. Southampton, UK: Sparkling Books. Original title Psychologie des Foules, first English translation in 1896.

Margry, Peter Jan \& Sánchez-Carretero, Cristina 2011. Rethinking memorialization: The concept of grassroots memorials. In: Peter Jan Margry \& Cristina SánchezCarretero (eds.) Grassroots memorials. The politics of memorializing traumatic death. Oxford: Berghahn Books, pp. 1-50.

Ogunlade, James O. 1979. Personality characteristics related to susceptibility to behavioral contagion. Social Behavior and Personality: an international journal, 7 (2), pp. 205-208.

Phillips, David P. 1974. The Influence of Suggestion on Suicide: Substantive and Theoretical Implications of the Werther Effect. American Sociological Review, 39 (3), pp. 340-354.

Rajković, Zorica 1988a. Znamenje smrti [Roadside Memorials Signs for Traffic Accident Victims]. Rijeka, Zagreb: Izdavački Centar Rijeka, Zavod za Istraživanje Folklore. Rajković, Zorica 1988b. Roadside memorial signs for traffic accident victims. Narodna Umjetnost, 2, pp. 167-180.

Redl, Fritz 1942. Group Formation and Leadership. Psychiatry, 5 (4), pp. 575-584.

Santino, Jack 2006. Performative Commemoratives: Spontaneous Shrines and Public Memoralization of Death. In: Jack Santino (ed.) Spontaneous Shrines and Public Memoralization of Death. New York, Basingstoke: Palgrave Macmillan, pp. 5-15.

Santino, Jack 2010. Spontaneous shrines, memorialization, and the public ritualesque. Ritsumeikan University Institute for Research in Humanities Bulletin, 94, pp. 1-65.

Stahl, Irina 2010. Les croix de la ville de Bucarest. Problèmes de sociologie religieuse. Dying and Death in $18^{\text {th }}-21^{\text {st }}$ century Europe: Refiguring death rites in Europe (Special issue). Annales Universitatis Apulensis (Historica series). Cluj-Napoca: Accent, pp. 387-411.

Stahl, Irina 2013. Sudden death memorials in Bucharest: Mortuary practices and beliefs in an urban context. Procedia. Social and Behavioral Sciences, 92. Elsevier, pp. 893-898.

Stephenson, Geoffrey M. \& Fielding, Geoffrey T. 1971. An experimental study of the contagion of leaving behavior in small gatherings. Journal of Social Psychology, 84 (1), pp. 81-91.

Thorpe, William H. 1956. Learning and Instinct in Animals. London: Mathuen.

Turner, Ralph H. 1964. Collective Behavior and Conflict: New Theoretical Frameworks. The Sociological Quarterly, 5 (2), pp. 122-132.

Wheeler, Ladd 1966. Towards a theory of behavioral contagion. Psychological Review, 73 (2), pp. 179-192.

Yudkina, Anna \& Sokolova, Anna 2014. Roadside Memorials in Contemporary Russia: Folk Origins and Global Trends. Religion and Society in Central and Eastern Europe 7 (1), pp. 35-51. 